\title{
Relatórios
}

\section{Violência doméstica e suas diferentes manifestações}

\author{
Vivian Peres Day* \\ Lisieux Elaine de Borba Telles* \\ Pedro Henrique Zoratto* \\ Maria Regina Fay de Azambuja** \\ Denise Arlete Machado* \\ Marisa Braz Silveira*** \\ Moema Debiaggi**** \\ Maria da Graça Reis ${ }^{\star \star * * *}$ \\ Rogério Göettert Cardoso* \\ Paulo Blank*
}

"A violência é, em primeiro lugar, os outros".

Alain Teyresite

\section{INTRODUÇÃO}

"Existe um meio de libertar os homens da maldição da guerra?", Einstein surpreende Freud na famosa troca de correspondência entre os dois gênios. A resposta é rápida: "em princípio, os conflitos de interesse entre os homens são solucionados mediante o uso da força". Explica Freud que a evolução tecnológica e intelectual pode e, muitas vezes, está a serviço de estimular o poder pelas armas ou pelo conhecimento. O objetivo seguiria sendo o mesmo, aniquilar o outro. O respeito ao inimigo vem

\footnotetext{
* Psiquiatra, sócio efetivo da SPRS.

** Procuradora de Justiça do Ministério Público do Estado do RS, especialista em violência doméstica pela USP.

*** Pediatra, especialista em violência doméstica pela USP.

**** Arquiteta, docente da PUCRS

${ }^{* * * * *}$ Defensora Pública do Estado do RS.
}

da necessidade de utilizar a vítima para seus propósitos, bastando mantê-la subjugada e atemorizada. Essas são reflexões que seguem atuais, escritas sob a égide da Segunda Guerra Mundial. Partindo do "filicídio institucionalizado" representado pelos conflitos mundiais, conclui-se que as aflições dos grandes mestres sobre as tendências autodestrutivas da humanidade resistem, apesar dos reiterados esforços da sociedade em explicá-las e evitá-las.

Partindo da experiência em estudar e acompanhar vítimas e perpetradores de violência, na experiência diária como psiquiatras forenses, membros do judiciário, médicos que atendem a realidade dos ambulatórios e dos centros de triagem, estudiosos de urbanismo e outros determinantes sociais, os autores agruparam suas experiências e conhecimentos para refletir e propor alternativas para lidar com um dos ângulos mais cruéis do crime, aquele que atinge os mais fracos por limitações físicas, emocionais ou sociais. Foi realizada pesquisa bibliográfica recente, ampla e atual, buscando contemplar os diferentes vértices do tema. $O$ enfoque multidisciplinar é, já, uma das propostas. O problema da violência intrafamiliar e do-

Recebido em 24/01/2003. Revisado em 25/01/2003. Aprovado em 18/03/2003. 
méstico é complexo e árido.

A antiga idéia de que o delinqüente era um estranho que se esconderia numa rua escura vem mudando sua face, e à luz observa-se feições bastante conhecidas, familiares. Hoje, está mais claro que falamos de muitas guerras. Os homens participam dos conflitos das ruas, são vítimas mais freqüentes de homicídios, ocorridos entre desconhecidos, atingindo principalmente os jovens. Entre 20 e 29 anos, a proporção é de 15 vezes para um de óbitos por projétil de arma de fogo, de homens em relação às mulheres da mesma faixa etária ${ }^{2}$. No presente trabalho, abordar-se-á o tipo de violência que mais acomete mulheres, crianças e adolescentes, além de idosos e deficientes físicos e mentais. Trata-se de atos violentos que acontecem dentro dos lares, onde a taxa de homicídios é menor, mas o prejuízo individual, familiar e social é catastrófico.

Entende-se por violência intrafamiliar:

"toda ação ou omissão que prejudique o bem-estar, a integridade física, psicológica ou a liberdade e o direito ao pleno desenvolvimento de um membro da família. Pode ser cometida dentro e fora de casa, por qualquer integrante da família que esteja em relação de poder com a pessoa agredida. Inclui também as pessoas que estão exercendo a função de pai ou mãe, mesmo sem laços de sangue".

O termo doméstico incluiria pessoas que convivem no ambiente familiar, como empregados, agregados e visitantes esporádicos.

As estatísticas mostram a magnitude do problema. Em 1997, em pesquisa do governo gaúcho, em uma amostra de 1579 crianças em "situação de rua", 23,4\% não retornavam para casa em função de maus-tratos. Flores e cols. estimaram que $18 \%$ das jovens porto-alegrenses, abaixo dos 18 anos, haviam sido vítimas de abuso sexual por familiares ${ }^{3}$. John Sargent, visitante da última jornada de psiquiatria dinâmica, ocorrida em 2002, afirmou em conferência proferida no evento, que 1 para 5 meninas e 1 para cada 10 meninos são vítimas de abuso sexual no mundo inteiro.

A Constituição Federal e o Estatuto da Criança e do Adolescente pssam a ser os novos paradigmas para o sistema de Justiça, para a sociedade e para o Brasil como um todo. A nova legislação, signatária da Doutrina da Proteção Integral, reconhece direitos à criança e ao adolescente, respeitando seu estágio de desenvolvimento ${ }^{4}$. É uma das legislações mais avançadas do mundo, que pouco a pouco começa a ser implementada. É recente para a criança brasileira ter este status de pessoa, assim como para a população feminina que, no sec. XX, conquistou significativos espaços e também ônus sociais.

O aumento da expectativa de vida tornou o idoso uma nova realidade a ser absorvida pela sociedade. Esta evolução permitiu que se abrisse com mais clareza o ambiente privativo dos lares, expondo suas mazelas.

A hipótese de que o ambiente familiar, pelas ligações afetivas, protegeria seus membros mais vulneráveis, tem se mostrado bastante falha. Os crimes cometidos por doentes mentais de grande repercussão social e na mídia passavam a falsa idéia de que atos desta natureza seriam atos de exceção cometidos por psicóticos, de forma imprevisível, restritos a situações raras, infortúnios de difícil prevenção.

A psiquiatria forense tem tido um trabalho específico, nobre, de atender agressores de alta periculosidade em grandes manicômios do mundo. A grande revolução farmacológica e o conseqüente aumento do convívio dos doentes mentais na comunidade devolve à sociedade as identificações projetivas a eles destinadas. O rico convívio dos autores apresentou com clareza esta nova realidade, os delitos cometidos por psicóticos são uma minoria, com características não menos relevantes, mas, sem dúvida, numericamente pouco expressiva, comparados aos outros fatores que colaboram para a disseminada, contínua e cumulativa violência doméstica que atinge todas as populações do mundo, independente de nível cultural, social e econômico.

Existem quatro formas mais comuns de violência intrafamiliar: física, psicológica, negligência e sexuaR,5.

A violência física ocorre quando alguém causa ou tenta causar dano por meio de força física, de algum tipo de arma ou instrumento que possa causar lesões internas, externas ou ambas.

A violência psicológica inclui toda ação ou omissão que causa ou visa a causar dano à auto-estima, à identidade ou ao desenvolvimento da pessoa.

A negligência é a omissão de responsabilidade de um ou mais membros da família em relação a outro, sobretudo àqueles que precisam de ajuda por questões de idade ou alguma condição física, permanente ou temporária

A violência sexual é toda ação na qual uma pessoa, em situação de poder, obriga uma ou- 
tra à realização de práticas sexuais, utilizando força física, influência psicológica ou uso de armas ou drogas.

Em função das peculiaridades do tema, o trabalho irá descrever as diferentes formas, utilizando como parâmetro principal as vítimas preferenciais para fins de tornar mais objetivo o relato.

\section{HISTÓRICO DO PROBLEMA NO BRASIL E NO MUNDO}

A preocupação com os direitos da criança e do adolescente trouxe à tona o problema dentro dos lares; a história do direito da criança confunde-se com a evolução da abordagem da violência doméstica, por isso, o histórico enfatizará este aspecto, ressaltando uma trajetória de abusos, maus-tratos e um processo de humanização da justiça.

Quanto mais regressamos na história, maiores as chances de depararmo-nos com a falta de proteção jurídica à criança, aumentando as probabilidades de que tivessem sido abandonadas, assassinadas, espancadas, aterrorizadas e abusadas física e sexualmente. Exemplos são colhidos ao longo da história, assinalando-se que, no Oriente Antigo, o Código de Hamurábi (1728/1686 a.C.), em seu art. 192 , previa o corte da língua do filho que ousasse dizer aos pais adotivos que eles não eram seus pais, assim como a extração dos olhos do filho adotivo que aspirasse voltar à casa dos pais biológicos, afastando-se dos pais adotantes (art. 193). Punição severa era aplicada ao filho que batesse no pai. Segundo o Código de Hamurábi, a mão do filho, considerada o órgão agressor, era decepada (art. 195). Em contrapartida, se um homem livre tivesse relações sexuais com sua filha, a pena aplicada ao pai limitava-se à sua expulsão da cidade (art. 154). Em Roma, a Lei das XII Tábuas, entre os anos 303 e 304 , permitia ao pai matar o filho que nascesse disforme, mediante o julgamento de cinco vizinhos (Tábua Quarta) ${ }^{6}$.

No período que antecedeu ao século XVIII, surge a utilização dos castigos, da punição física, dos espancamentos através de chicote, ferros e paus às crianças. Justificavam os pensadores da época que os pais deveriam cuidar para que seus filhos não recebessem más influências. Acreditavam que as crianças poderiam ser moldadas de acordo com os desejos dos adultos. Novas concepções, como a contribuição de John Locke, em sua obra intitulada Da educação das crianças, um dos clássicos da pedagogia européia do século XVIII, alertava os pais para a importância da prevenção "como o meio mais eficaz de preservar a saúde dos filhos". O mesmo autor propôs que se desse "atenção rigorosa ao desenvolvimento intelectual e à capacidade de autocontrole da criança". Assim como Locke, também Rousseau, no século XVIII, contribuiu para o entendimento do significado da infância. Afirmava que "a criança é importante em si mesma, e não meramente como um meio para um fim", além de sustentar que "a infância é o estágio da vida em que o homem mais se aproxima do 'estado de natureza'”. Na Inglaterra, em 1780, "as crianças podiam ser condenadas por qualquer um dos mais de duzentos crimes cuja pena era o enforcamento". Entre 1730 e 1779, metade das pessoas que morreram em Londres tinha menos de cinco anos de idade ${ }^{8}$. Somente no século XIX, o filho passa a ser objeto de investimento afetivo, econômico, educativo e existencial. É neste período que passa a ocupar a posição central dentro da família que, por sua vez, passa a ser um "lugar de afetividade, onde se estabelecem relações de sentimento entre o casal e os fiIhos, lugar de atenção (bom ou mau)". Surge o interesse de filantropos, médicos e estadistas em auxiliar as crianças provenientes de famílias pobres. Em 1841, é editada uma das primeiras leis sobre a limitação do tempo de trabaIho nas fábricas, voltada à proteção da criança, "marcando a primeira guinada de um direito liberal rumo a um direito social"10. Na Europa, a partir de 1850, percebe-se o filho como sendo objeto de amor dos pais, e a sua morte passa a ser motivo de luto para o adulto. É, nesse período, que os manuais de educação sinalizam para a prece infantil e maternal, forma de aproximar mães e filhos em torno da aprendizagem da oração.

A chegada das primeiras crianças ao Brasil, mesmo antes do seu descobrimento oficial, foi marcada por situações de desproteção. $\mathrm{Na}$ condição de órfãs do Rei, como grumetes ou pagens, eram enviadas com a incumbência de casarem com os súditos da Coroa. Poucas muIheres vinham nas embarcações, e as crianças eram "obrigadas a aceitar abusos sexuais de marujos rudes e violentos"1. Por ocasião dos naufrágios, comuns na época, eram deixadas de lado pelos adultos, entregues à fúria do mar.

No final do século XIX, as descobertas de Freud e outros pensadores abriram caminho para novos entendimentos sobre a infância:

"Freud e Dewey cristalizaram o paradigma básico da infância, que vinha sendo formado desde a invenção da prensa tipográfica: 
a criança como aluno ou aluna, cujo ego e individualidade devem ser preservados por cuidados especiais, cuja aptidão para o auto-controle, a satisfação adiada e o pensamento lógico devem ser ampliados, cujo conhecimento da vida deve estar sob controle dos adultos"s

Até o final do século XIX e início do século $\mathrm{XX}$, a criança foi vista como um instrumento de poder e de domínio exclusivo da Igreja. Somente no início do século XX, a medicina, a psiquiatria, o direito e a pedagogia contribuem para a formação de uma nova mentalidade de atendimento à criança, abrindo espaços para uma concepção de reeducação, baseada não somente nas concepções religiosas, mas também científicas.

O primeiro estudo científico sobre a violência contra a criança foi realizado na França, em 1860, pelo Prof. Ambroise Tardieu, presidente da Academia de Medicina de Paris, estabelecendo o conceito de criança maltratada. Nos EEUU, a violência doméstica contra crianças veio ao conhecimento do público através do caso da menina Mary Ellen, de 8 anos, que foi severamente maltratada, resultando na fundação da Sociedade de Prevenção da Crueldade contra Criança em 1874. No século XX, a redescoberta da violência doméstica foi assinalada por Caffey (1946), que descreveu a síndrome de crianças com hematomas subdurais associados a múltiplas fraturas de ossos longos, de origem traumática. Até 1960, pensava-se que a violência contra a criança era rara, em parte porque a disciplina física de crianças era mais aceita; em parte, pela sua negação. Em 1962, Kempe et al. publicaram um importante artigo no JAMA, descrevendo a síndrome da criança espancada, tornado o problema da lesão infligida um problema evidente para a comunidade. Nos anos 70, em todo EEUU, foram aprovadas leis nas quais requeria-se a designação de pessoas para notificar a violência doméstica contra a criança e o adolescente. Isso acabou provocando um melhor entendimento da extensão da violência sexual contra crianças. Era sabido que o incesto ocorria, mas muitos acreditavam que deveria ser muito raro e que se sucedia apenas entre famílias muito comprometidas ${ }^{6}$.

Embora Freud já tenha abordado o assunto, em 1919, foi com a publicação da obra "Síndrome da Criança Espancada", de Kempe e colaboradores, em 1962, em Chicago, que o maltrato à infância começou a ser aceito como objeto de investigação, passando a chamar a atenção dos profissionais da saúde e do público em geral para a necessidade de proteção à criança $^{12}$.

Em 1924, a União Internacional do Fundo para a Salvação de Crianças estabeleceu, através da Declaração de Genebra, a primeira tentativa de codificar os direitos elementares das crianças, merecendo a ratificação pela Liga das Nações. O texto, composto de cinco artigos, embora sem caráter coercitivo, foi o marco inicial, em nível internacional, na luta pelos direitos da infância. Em 1948, a Declaração Universal dos Direitos Humanos das Nações Unidas reafirma o direito a cuidados e assistência especiais a esta parcela da sociedade. No mesmo ano, a Declaração de Genebra, através de revisão e ampliação, veio a se constituir na base para a Declaração dos Direitos da Criança, adotada pela Assembléia Geral da ONU em 1959. Dez princípios compõem o documento que passou a incorporar novas diretrizes de proteção dos direitos humanos aplicáveis à infância. Sua importância deve-se ao fato de ter contribuído para o chamamento dos pais, dos cidadãos, das organizações não-governamentais, das autoridades e dos governos ao reconhecimento dos direitos da criança.

A evolução das ciências, em sentido amplo, influenciou no surgimento das diversas legislações protetivas à criança, permitindo constatar que, no Brasil, de res, isto é, de simples objeto de satisfação dos desejos dos adultos, passou, na pós-modernidade, mais especificamente no ano de 1988, à condição de sujeito de direitos, com a introdução do art. 227 da Constituição Federal. Cada vez mais, faz-se necessário um trabalho interdisciplinar, em que "médicos, psicólogos, pedagogos e assistentes sociais, profissionais que, no exercício de suas atividades, podem estar envolvidos com o atendimento e a defesa de direitos de crianças e adolescentes e suas violações". ${ }^{13}$

Em que pesem os avanços registrados ao longo da história, tanto no aspecto social, médico, como jurídico, as crianças vítimas de violência, no Brasil, ainda formam um grande contingente, no qual encontramos, basicamente, "a infância pobre, vítima de violência social mais ampla; a infância explorada, vítima de violência no trabalho; a infância torturada, vítima da violência institucional; a infância fracassada, vítima da violência escolar; a infância vitimizada, vítima da violência doméstica". ${ }^{14}$

Entre as inovações operadas a partir de 1988, de basilar relevância é o chamamento lançado à família, à sociedade e ao poder público no que diz respeito ao atendimento dos direi- 
tos fundamentais da criança, elevados ao patamar de prioridade absoluta. De todos os setores, há de vir o envolvimento, recaindo, de igual forma, sobre todos a responsabilização pelo descumprimento dos novos deveres, hoje guindados à condição de direitos da infância. Negar à criança os direitos humanos fundamentais, frente ao disposto na nova Carta, significa negar-Ihe a essência da própria dignidade humana. O moderno paradigma da infância passa a ser também o moderno paradigma da vida adulta ${ }^{8}$.

\section{DISCUSSÃO}

\section{Violência doméstica contra crianças} $e$ adolescentes

“...as crianças confiam nos adultos. Confiam como uma bússola ou um oráculo. Agarram-se a seus atos e palavras como uma bóia no oceano ameaçador de uma vida à qual recém foram apresentadas"15 (Eliane Brum).

No Brasil, assim como em outras partes do mundo, em diferentes culturas e classes sociais, independente de sexo ou etnia, crianças e adolescentes são vítimas cotidianas da violência doméstica, sendo este um fenômeno universal e endêmico.

Os casos registrados em todo o país, em delegacias, conselhos tutelares, hospitais e institutos médico-legais são apenas um alerta; não revelam a verdadeira dimensão do problema. Os levantamentos oficiais sobre o fenômeno são precários e os dados obtidos são uma pequena parte do real, a "ponta de um Iceberg". " $A$ cifra negra - número de casos não notificados será maior ou menor conforme seja mais ou menos amplo o "complô de silêncio" de que muitas vezes participam os profissionais, os vizinhos, os parentes, familiares e até a própria vítima". 16

A violência contra crianças e adolescentes "implica, de um lado, transgressão do poder de proteção do adulto e, de outro, coisificação da infância, isto é, negação do direito que Crianças e Adolescentes têm de ser tratados como sujeitos e pessoas em condição peculiar de desenvolvimento"14

Pode ser subdividida da seguinte forma:

\section{Violência física:}

É a mais freqüente. Como a vítima é indefesa e está em desenvolvimento, o caráter disci- plinador da conduta exercida pelo progenitor ou por quem o substitua é um aspecto bastante relevante, variando de uma "palmada", a espancamentos e homicídios. Não há um consenso quanto aos métodos que se consideram violentos no processo educacional entre pais e filhos, embora mais recentemente, a tendência mundial é considerar violência qualquer modalidade ou ato disciplinar que atinja o corpo da criança ou adolescente. Em alguns países, a palmada é proibida por lei. Segundo estatísticas, a mãe é a maior agressora nestes casos, embora os pais, em números absolutos, prevaleçam. Famílias uniparentais aumentam em $80 \%$ o risco.

\section{Violência sexual:}

A prática sexual com indivíduos menores de 14 anos, com consentimento ou não das mesmas, é considerada por lei "violência presumida", ou seja, não são considerados capazes de tomar decisões desta natureza. A abuso sexual inclui desde carícias, olhares perturbadores, até delitos de extrema violência e morte. As famílias propiciadoras deste tipo de violência são mais velhas, têm mais chance de incluírem genitores substitutos. Os pais adotivos apresentam o dobro de chance de cometerem abuso sexual.

\section{Violência psicológica:}

É a forma mais subjetiva, embora seja muito freqüente a associação com agressões corporais. Deixa profundas marcas no desenvolvimento, podendo comprometer toda a vida mental.

\section{Negligência:}

Configura-se quando os pais ou responsáveis falham em prover cuidados de saúde, nutrição, higiene pessoal, vestimenta, educação, habitação e sustentação emocional, e quando tal falha não é o resultado das condições de vida além do seu controle. Recentemente, o termo vem sendo ampliado para incorporar a chamada supervisão perigosa. É mais freqüente em famílias jovens, nas quais a criança está doente e é mantida pela mãe. A uniparentalidade aumenta, em $220 \%$, o risco de negligência ${ }^{3}$.

A violência contra crianças e adolescentes pode afetar todos os aspectos da vida da criança, como psicológicos, físicos, comportamentais, acadêmicos, sexuais, interpessoais, espirituais, comprometendo a auto-estima e 
estimulando a ocorrência de violência subseqüente.

Há uma tendência em subestimar os efeitos da violência doméstica contra a criança e o adolescente como menos sérios, acreditando que o impacto parece ser temporário e desaparecer no transcorrer do desenvolvimento infantil. O trauma infantil não deve ser desconsiderado por seus efeitos a longo prazo não serem evidenciados de imediato. Deve ser reconhecido como um sério problema da infância. Mesmo que crianças vitimizadas sejam retiradas de suas casas, os efeitos da experiência vivida repercutirão em toda sua vida.

\section{Manifestações psicológicas:}

Danos imediatos: • pesadelos repetitivos; • ansiedade, raiva, culpa, vergonha; - medo do agressor e de pessoa do mesmo sexo; • quadros fóbico-ansiosos e depressivos agudos. - queixas psicossomáticas; • isolamento social e sentimentos de estigmatização.

Danos tardios: $\bullet$ aumento significativo na incidência de transtornos psiquiátricos; - dissociação afetiva, pensamentos invasivos, ideação suicida e fobias mais agudas; • níveis intensos de ansiedade, medo, depressão, isolamento, raiva, hostilidade e culpa; • cognição distorcida, tais como sensação crônica de perigo e confusão, pensamento ilógico, imagens distorcidas do mundo e dificuldade de perceber realidade; • redução na compreensão de papéis complexos e dificuldade para resolver problemas interpessoais.

Apesar do crescente interesse nas conseqüências da violência doméstica contra a criança e o adolescente, há poucos estudos sobre os efeitos psicológicos a longo prazo na população em geral. Sabe-se que, na população carcerária, há uma grande porcentagem de indivíduos com história de violência na infância e que estes tendem a apresentar mais problemas psiquiátricos, tais como transtorno de estresse pós-traumático, depressão maior, transtornos de personalidade múltipla, transtornos de personalidade borderline, abuso de substância e comportamento anti-social.

\section{Manifestações da violência física:}

O local mais acometido pela violência física no corpo da criança e do adolescente é a pele. A lesão pode incluir desde vermelhidão, equimoses ou hematomas, até queimaduras de
1ํ a 3o grau. É comum encontrarem-se marcas do instrumento utilizado para espancar crianças ou adolescentes; elas podem apresentar forma de vara, de fios, de cinto ou até mesmo da mão do agressor.

Uma das manifestações mais graves da violência física contra a criança é a Síndrome do bebê sacudido (Shaken Baby Syndrome). Caracteriza-se por lesões de gravidade variável, que ocorrem quando uma criança, geralmente um lactente, é severa ou violentamente sacudida. Pode causar cegueira ou lesões oftalmológicas, atraso no desenvolvimento, convulsões, lesões da espinha, lesões cerebrais, culminando com a morte.

\section{Manifestações de negligência:}

A negligência pode envolver falha na alimentação adequada, em providenciar cuidados médicos ou em proteger a criança de perigos, atraso nas vacinas, perder documentos, deixar crianças sozinhas ou fora da escola.

\section{Manifestações da violência sexual:}

A curto prazo: - secularização excessiva, como atividade masturbatória compulsiva; • distúrbios do sono, aprendizagem, alimentação e conduta isolada • banhos freqüentes • sintomas psicóticos - quadros ansiosos, obsessivo-compulsivos, depressão, • expressões repetidas através de gestos; • sentimentos de rejeição, confusão, humilhação, vergonha e medo.

A longo prazo: - abuso de álcool e outras drogas; • promiscuidade; • disfunções sexuais. - Coitofobia • Disfunções menstruais • imagem corporal pobre; - sexualização ou abuso de seus filhos; - comportamento auto e heterodestrutivo; • baixa auto-estima e culpa; • sentimentos de vergonha e traição; • dist. psiquiátricos; • homossexualismo.

Está bem estabelecido que os efeitos da violência doméstica contra a criança e o adolescente podem durar a vida inteira e diminuirem significativamente as chances de uma criança ter um desenvolvimento integral e saudável. Embora se enfatize que o problema atinge os quatro cantos da Terra de forma epidêmica, é relevante que se ressalte que a pobreza, de uma forma geral, aumenta a incidência de doença mental e a possibilidade de ocorrência de conduta violenta contra crianças. Aumenta em 22 vezes o risco de maus-tratos, 56 vezes, 
o de negligência educacional e 60 vezes, o risco de morte por abuso e/ou negligência.

O Relatório de 2002, elaborado pela Organização Mundial de Saúde, aponta que, na maioria dos países, meninas apresentam maior risco do que meninos para o infanticídio, abuso sexual, negligência física e nutricional, assim como para a prostituição forçada. Em muitos países, as meninas ou não podem estudar ou são mantidas em casa para ajudar a cuidar dos irmãos ou ajudar, através do trabalho, na renda familiar. Segundo o documento, os meninos, em vários países, apresentam maior risco de sofrer castigos físicos mais graves. Da mesma forma, bebês prematuros, gêmeos e deficientes físicos ou mentais demonstram estar sob maior risco de abuso físico e negligência, características capazes de interferir na formação do vínculo ou do apego, tornando esta população mais vulnerável ao abuso, embora tais fatores não apareçam como preponderantes para a violência quando outros fatores são considerados, como variantes parentais e sociais. De outro lado, dados de estudos realizados em países geográfica e culturalmente distintos, como a China, Colômbia, Egito, Índia, México, Filipinas, África do Sul e Estados Unidos encontram forte correspondência entre a violência entre os casais e o abuso infantil. Crianças que testemunham violência, por sua vez, estão mais predispostas a reproduzir, quando adultas, relacionamentos disfuncionais com suas próprias famílias.

No que se refere ao sistema de Justiça, uma revisão de casos de ação penal envolvendo crianças abusadas descobriu que $72 \%$, das 451 alegações recebidas no período de dois anos, foram considerados casos prováveis de abuso sexual. Acusações formais, entretanto, foram feitas em pouco mais da metade destes casos. O documento aponta, ainda, que, em muitos países, há pouco reconhecimento de abuso infantil entre o público ou profissionais da saúde ${ }^{12}$

\section{Violência contra a Mulher}

Em todo mundo, pelo menos uma em cada três mulheres já foi espancada, coagida ao sexo ou sofreu alguma outra forma de abuso durante a vida. O agressor é, geralmente, um membro de sua própria família.

A violência contra as mulheres é o tipo mais generalizado de abuso dos direitos humanos no mundo e o menos reconhecido. A Assembléia Geral das Nações Unidas, de 1993, definiu oficialmente a violência contra as mu-
Iheres, como:

"Qualquer ato de violência de gênero que resulte ou possa resultar em dano físico, sexual, psicológico ou sofrimento para a mulher, inclusive ameaças de tais atos, coerção ou privação arbitrária da liberdade, quer ocorra em público ou na vida privada". ${ }^{17}$

A agressão do parceiro íntimo - também conhecida como violência doméstica, maus-tratos ou espancamento da esposa - é, quase sempre, acompanhada de agressão psicológica e, de um quarto a metade das vezes, também de sexo forçado.

A violência contra as mulheres é diferente da violência interpessoal em geral. Os homens têm maior probabilidade de serem vítimas de pessoas estranhas ou pouco conhecidas, enquanto que as mulheres têm maior probabilidade de serem vítimas de membros de suas próprias famílias ou de seus parceiros íntimos. $\mathrm{Na}$ sua forma mais grave, a violência leva à morte da mulher. Sabe-se que de 40 a $70 \%$ dos homicídios femininos, no mundo, são cometidos por parceiros íntimos. Em comparação, os percentuais de homens assassinados por suas parceiras são mínimos e, freqüentemente, nestes casos, as mulheres estavam se defendendo ou revidando o abuso sofrido. A pobreza aumenta a probabilidade das mulheres serem vítimas de violência.

$\mathrm{Na}$ violência doméstica contra a mulher, o abuso pelo parceiro íntimo é mais comumente parte de um padrão repetitivo, de controle e dominação, do que um ato único de agressão física. O abuso pelo parceiro pode tomar várias formas, tais como:

- Agressões físicas como golpes, tapas, chutes e surras, tentativas de estrangulamento e queimaduras, quebras de objetos favoritos, móveis, ameaças de ferir as crianças ou outros membros da família;

- Abuso psicológico por menosprezo, intimidações e humilhação constantes;

- Coerção sexual;

- Comportamentos de controle tipo isolamento forçado da mulher em relação à sua família e amigos, vigilância constante de suas ações e restrição de acesso a recursos variados.

O que provoca a violência contra as mulheres? A tendência atual dos pesquisadores é de considerar a interação de diferentes fatores pessoais, situacionais e socioculturais combinando-se para provocar o abuso.

Como fatores pessoais do agressor, destacamos: 
- Ser homem;

- Ter presenciado violência conjugal quando criança;

- Ter sofrido abuso quando criança;

- Pai ausente;

- Consumo de bebidas alcoólicas e/ou drogas.

Como fatores de risco da relação:

- Conflito conjugal;

- Controle masculino da riqueza e da tomada de decisões na família;

Como fatores da comunidade:

- Pobreza, desemprego;

- Associação a amigos delinqüentes;

- Isolamento das mulheres e famílias.

Como fatores da sociedade:

- Normas socioculturais que concedem aos homens o controle sobre o comportamento feminino;

- Aceitação da violência como forma de resolução de conflitos;

- Conceito de masculinidade ligado à dominação, honra ou agressão;

- Papéis rígidos para ambos os sexos.

Reação das mulheres à agressão:

As reações femininas são diversas, algumas resistem, outras fogem e outras tentam manter a paz, submetendo-se às exigências de seus maridos. A reação da mulher à violência é freqüentemente limitada pelas opções à sua disposição. Os motivos mais alegados para continuar em um relacionamento abusivo são: medo de represália, perda do suporte financeiro, preocupação com os filhos, dependência emocional e financeira, perda de suporte da família e dos amigos, esperança de que "ele vai mudar um dia".

Sabe-se que fatores abaixo descritos também contribuem para manutenção na relação conflitiva:

- Repetição de modelo familiar/parental violento:

- Vivências infantis de maus-tratos, negligência, rejeição, abandono e abuso sexual;

- Casamento como forma de fugir da situação familiar de origem, sendo o parceiro e relacionamento idealizados;

- Sintomas depressivos;

- Sentimento de responsabilidade pelo comportamento agressivo do companheiro;

- Ausência de uma rede de apoio eficaz no que se refere à moradia, escola, creche, saúde, atendimento policial e da justiça.
Apesar das dificuldades, muitas mulheres acabam abandonando os parceiros violentos. As mulheres mais jovens são mais propensas a abandonar estes relacionamentos mais cedo. Situações como aumento do nível da agressão, violência afetando os filhos e apoio sociofamiliar são determinantes na decisão de sair do relacionamento. A mulher entra em um processo de quebra de sua negação, racionalização, culpa e submissão, passando, então, a se identificar com outras pessoas na mesma situação. Nesse período, é comum o abandono e retorno ao relacionamento várias vezes, antes de deixá-lo definitivamente.

Infelizmente, mesmo após o término da relação, a violência pode continuar e até aumentar. O maior risco de ser assassinada pelo marido ocorre após a separação.

\section{CONSEQÜÊNCIAS DA VIOLÊNCIA}

As conseqüências negativas da agressão atingem a saúde física e emocional das mulheres, o bem-estar de seus filhos e até a conjuntura econômica e social das nações, seja imediatamente ou a longo prazo, conforme e experiência dos autores e a bibliografia já citada.

Dentre os quadros orgânicos resultantes, encontram-se lesões, obesidade, síndrome de dor crônica, distúrbios gastrintestinais, fibromialgia, fumo, invalidez, distúrbios ginecológicos, aborto espontâneo, morte.

Muitas vezes, as seqüelas psicológicas do abuso são ainda mais graves que seus efeitos físicos. A experiência do abuso destrói a autoestima da mulher, expondo-a a um risco mais elevado de sofrer de problemas mentais, como depressão, fobia, estresse pós-traumático, tendência ao suicídio e consumo abusivo de álcool e drogas.

A violência doméstica, estupro e abuso sexual na infância estão entre as causas mais comuns de transtorno de estresse pós-traumático em mulheres. Nesta patologia, a paciente experimenta sensação muito forte de estar revivendo o evento traumático, assume conduta evitativa, vive apatia emocional, tem dificuldades para adormecer, se concentrar e assustase com facilidade.

O impacto de tipos diferentes de abuso e de múltiplos eventos ao longo do tempo parece ser cumulativo. Para algumas mulheres, o peso destas agressões e sua desesperança parecem tão intoleráveis que podem levá-las ao suicídio.

As crianças que presenciam a violência 
conjugal enfrentam risco mais elevado de apresentarem ansiedade, depressão, baixo rendimento escolar, baixa auto-estima, pesadelos, conduta agressiva e maior probabilidade de sofrerem abusos físicos, sexuais ou emocionais.

\section{Violência contra o deficiente e o idoso}

No presente artigo, já está suficientemente relatado que toda situação de vulnerabilidade física ou mental é geradora potencial de violência. As limitações mobilizam frustração e sobrecarga dentro do ambiente familiar e contribuem para a eclosão de atitudes de negligência e abusos. Tanto idosos como deficientes sofrem também de violência física, psicológica, sexual e negligência, com as peculiaridades específicas. Uma das mais comuns é a financeira, o uso das aposentadorias pela família e a desatenção das necessidades do idoso, culminando no abandono. Além de muitas outras, como maus-tratos físicos, estupro, maus cuidados de higiene, má nutrição, vestuário inadequado, escaras, impactação fecal, alopécia. Do ponto de vista psiquiátrico, há presença de comportamentos bizarros como embalar-se, chupar dedo e o surgimento de outros sintomas neuróticos e de conduta. Os recentes estudos ${ }^{2}$ sugerem que mulheres idosas, em situação de comprometimento cognitivo, físico e mental são as vítimas preferenciais. O idoso, muitas vezes, submetese por não ter como se proteger e por culpa, sente-se um "fardo" para os familiares.

É razoavelmente comum deficientes serem contidos por cordas, isolados em quartos sem ventilação e falta de estímulo. Ocorre também, administração exagerada de medicamentos. São privados de direitos civis, como convívio, privacidade, informação, visitas. As meninas sofrem mais abusos e são, freqüentemente, submetidas à prostituição.

\section{O doente mental como agressor e vítima:}

Segundo dados da $\mathrm{OMS}^{18}$, um doente mental numa família é uma grande sobrecarga. 0 grande movimento de limitação de vagas em hospitais psiquiátricos e a crescente inserção do doente mental na comunidade é uma nova realidade mundial. Se por um lado essa realidade torna a visão integrada e de inclusão na cidadania; por outro, exerce um grande fator de pressão familiar. A obtenção na rede pública de condições de manter o acompanhamento e a medicação são, na maioria das vezes, inacessíveis. Já está bem descrito que a periculosida- de potencial do paciente psicótico está diretamente relacionada com a falta de tratamento.

A família do doente vê-se onerada com a grande limitação que a doença exerce, impedindo-o de trabalhar. Representa um indivíduo frágil, incapacitado, desorganizado emocionalmente, que necessita de supervisão, tratamento adequado. As expectativas frustras da família muitas vezes desencadeiam ações de extrema violência por parte dos pacientes que se vêem sem condições de atendê-las. As mesmas razões também os tornam vítimas de violência física, negligência, abandono, abuso sexual, financeiro, aos quais se submetem por culpa e falta de recursos.

A doença mental expõe a alguns tipos de delitos, e a escolha de vítimas ocorre entre o círculo de proximidade, determinada pela interação familiar e a disponibilidade das vítimas, que se mostram vulneráveis por dois principais motivos. A vítima desconhece o potencial perigoso do doente por ser também comprometida psiquiatricamente ou não ter possibilidade de evitar o delito ou de defender-se.

Na população do Instituto Psiquiátrico Forense (I.P.F.) "Maurício Cardoso", há um predomínio de homens agressores, portadores de esquizofrenia e outras síndromes paranóides; as vítimas são, preferencialmente, suas mães e companheiras, utilizando objetos corto-contundentes, com alta incidência de homicídios e lesões graves. As mulheres doentes atingem seus filhos na grande maioria. A comorbidade com álcool e outras drogas é alta e a descontinuidade do tratamento, um forte fator de risco, sendo de $60 \%$ a população de egressos do sistema de saúde. No entanto, após a alta do IPF, incluindo um longo trabalho de re-inclusão, atendimento a familiares, fornecimento de passagens e medicação, encaminhamento a serviços ambulatoriais, a reincidência e reinternação passam a ser nulas.

A atividade delituosa do doente mental é bastante diferente da delinqüência em geral. A população prisional é masculina, jovem, de alta reincidência; os delitos são, preferencialmente, contra o patrimônio, e a vítima é desconhecida.

A importância da doença mental dentro da problemática da violência doméstica necessita ser bem esclarecida e adequadamente abordada, uma vez que são situações geralmente crônicas, com muitas evidências prévias, negadas ou mal manejadas. As conseqüências são, via de regra, irreversíveis, atingem todos os membros e várias gerações, perturbam a interação social de forma definitiva, afetando definitivamente as bases dos princípios afetivos, de se- 
gurança e de proteção.

Marchiore fala em fraturas ${ }^{19}$. A família se esfacela, parte se identifica com a vítima, parte com o agressor. Ocorrem em 3 níveis, a primeira relacionada à forma em que emerge a violência e a projeção dos membros da família sobre a vítima e o agressor. A segunda, no decorrer do processo, os testemunhos e o exame das circunstâncias do crime. A última ocorre em face do comportamento no pós-delito por parte do agressor. O grau de fratura pode ser total, parcial ou mínima, dependendo do grau de relação com o agressor. Essas fraturas conduzem a vários graus de prejuízo, como comportamentos autodestrutivos, suicidas, doenças mentais, principalmente, alcoolismo, depressão e psicossomatismos. Tais padrões podem comprometer várias gerações, em que parte se identifica com a perpetuação da conduta violenta e parte com a vitimização. A perda da figura paterna leva a prole a uma situação de grave dificuldade de sustentação emocional, financeira e ao estigma da internação compulsória do outro progenitor. $\mathrm{O}$ afastamento familiar longo expõe a uma reorganização familiar na qual o paciente não está mais incluído, perdendo seu lugar no afeto e no espaço doméstico.

\section{O uso de álcool e outras drogas}

A incidência de violência doméstica tem sido considerada maior em abusadores de substâncias psicoativas na maioria das sociedades e culturas e presente nos diferentes grupos econômicos. Desempenha um papel desencadeante de atos violentos pela ação desinibidora da censura, assumindo o agressor, condutas socialmente reprováveis.

Um estudo transversal de violência doméstica, na qual foram entrevistadas 384 mulheres casadas, numa cidade do México, encontrou uma prevalência de $42 \%$ de violência sexual, $40 \%$ de violência física e $38 \%$ de violência emocional. O estudo evidenciou que o antecedente de violência, uso de álcool e/ou outras drogas em algum membro da família, são fatores observados consistentemente em três dimensões exploradas ${ }^{20}$.

Um estudo de vítimas de agressão física, realizado num pronto-socorro em São Paulo, encontrou dados que corroboram a correlação de maior vitimização por agressão física e ingesta alcoólica ${ }^{21}$. Este risco não está relacionado só a consumidores pesados, mas também a bebedores eventuais, leves e moderados ${ }^{22}$. Assim, considera-se que os indivíduos intoxicados também podem estar mais propensos a sofrer algum tipo de violência.

O consumo de álcool e drogas ilícitas em indivíduos portadores de outros transtornos mentais como Esquizofrenia e Demências, assim como em pessoas com personalidade de características impulsivas e com pouca tolerância à frustração, pode ser considerado como potencializador e desencadeande de atos violentos.

\section{Comentários Finais}

O estudo da violência doméstica exige uma atitude de muita tolerância e sensibilidade. As emoções envolvidas despertam raiva, pena, rechaço, tristeza e impotência. A tendência da identificação com a vítima torna a tarefa da equipe de trabalho uma experiência, por vezes, dolorosa. A "estranheza", o sinistro freudiano, remonta o observador às vivências precoces vividas pelo bebê em seu desamparo, imerso em vivências de desprazer. Os conflitos presentes na mente da mãe persistem como marcas mnêmicas na vida mental do bebê, de uma forma mais ou menos intensa de acordo com a vivência pessoal. Situação esta com que todos, de uma forma ou de outra, identificam-se. A primeira reação é negar ou evitar, colaborando para o "muro de silêncio", onde a violência viceja.

O agressor tende a imobilizar a vítima, torna-a uma presa, despejando sobre ela suas necessidades narcísicas de se libertar de todo seu desconforto interno, ou pior, de usá-la para suas tendências sádicas de prazer.

Uma atitude de respeito e cautela é importante para a equipe de saúde. Examinar a situação com presteza, utilizando impressões e sensações da equipe pode ser um bom "norte". Toda a situação de violência doméstica é de difícil diagnóstico. É bem conhecido que só $10 \%$ das vítimas que passam por exame de corpo de delito apresentam lesões evidentes. A grande maioria sequer é denunciada; destas, poucas são confirmadas no exame, e ainda é muito comum a família estar ambivalente, retirar a queixa, envolvida com a proteção do agressor por muitos motivos, inclusive pobreza.

\section{Propostas de abordagem do ponto de} vista da saúde

A abordagem do problema necessita de muitas mãos, que juntas formam redes. Vemos que a evolução da vida moderna desencadeou muitas alterações que acabaram por fragilizar e isolar o núcleo familiar. Grande parte das crian- 
ças acabam por ser negligenciadas por suas jovens e solitárias mães, ignoradas em sua existência pelos pais, fisicamente agredidas pelos casais, abusadas sexualmente por padrastos. Um círculo perverso que revela um espaço conflitivo que perpassa várias instâncias que produzem e são produto de violência. É importante chamar atenção para o fato de que os serviços médico-hospitalares identificam menos casos de agressões múltiplas a crianças que os conselhos tutelares. Também as mulheres vítimas de abusos intrafamiliares, freqüentadoras assíduas de unidades de atendimento de saúde com queixas vagas, taxadas de "poliqueixosas", não têm o problema da vitimização diagnosticado.

Os profissionais da saúde mantêm uma posição de desinformação, indiferença, negação, preconceito e temor com respeito ao problema da violência doméstica e a suas conseqüências, assim como na detecção e prevenção de situações potencialmente perigosas, muitas vezes rotulando como "caso de IPF", na esperança de eximir-se de tomar atitudes. O medo de obrigações legais impede de tomar atitudes que pudessem auxiliar as vítimas. Este tema sequer faz parte dos programas das universidades, em sua maioria. A tendência é centrar em serviços com poucos recursos que tendem a seguir o mesmo trajeto das vítimas, poucos profissionais, isolados, desvalorizados, com enorme sobrecarga de trabalho.

O apoio a "espaços transicionais", como escolas, ainda hoje o maior ponto de amparo social da criança, pode aliviar o árido trabalho de acompanhar casos já de longa duração e péssimo prognóstico. São ainda os professores, apesar da grande falta de apoio, os que ainda mais detectam alterações e encaminham situações de suspeita. Ênfase em atividades de consultoria podem auxiliar nesta transição, que pode ser de grande ajuda. A equipe de saúde bem treinada pode detectar, documentar, abordar e acompanhar boa parte dos casos.

Nas tribos em que o grau de violência contra crianças é muito reduzido, o cuidado da criança é tarefa de todos.

\section{Propostas de abordagem do ponto de vista jurídico}

A violência doméstica, em face de suas características e múltiplas interferências no campo social, cultural, médico e legal, está a exigir uma abordagem transdisciplinar, caso se pretenda obter resultados mais favoráveis às vítimas, ao grupo familiar e à sociedade como um todo.

Há que se buscar, cada vez mais, desenvolver trabalhos e programas com abrangência mais ampla, para abarcar a vítima, o abusador e o restante do grupo familiar, em face das múltiplas facetas contempladas pela violência doméstica, em especial a violência intrafamiliar.

Para a implantação de programas que prestigiem uma abordagem transdisciplinar, há que se buscar capacitar, de forma continuada, as equipes profissionais envolvidas, no intuito de que possam se apropriar de conhecimentos básicos sobre saúde, direitos da criança, aspectos jurídicos que envolvem os procedimentos judiciais, a fim de que atuem de uma forma mais abrangente, evitando intervir sob um único enfoque. Intervenções isoladas, que não valorizem a constante comunicação entre os diversos profissionais, acabam por dificultar a continuidade do atendimento, propiciando, não raras vezes, o abandono do tratamento pela vítima e pelo grupo familiar, deixando de lado o abusador. É de Tilman Furniss que vem o alerta:

"Como um problema multidisciplinar genuíno e genérico, requer a estreita cooperação de uma ampla gama de diferentes profissionais com diferentes tarefas. Como um problema legal e terapêutico, requer, por parte de todos os profissionais envolvidos, o conhecimento dos aspectos criminais e de proteção da criança, assim como dos aspectos psicológicos"23.

A violência doméstica, de cunho intrafamiliar, com freqüência, vem acompanhada do segredo e da negação, fazendo com que muitos casos sequer cheguem ao sistema de Justiça ou mesmo ao sistema de Saúde. Outros, quando desvendados, já vinham sendo praticados por longos anos, prejudicando o êxito da intervenção. No que tange à criança e ao adolescente, nossa legislação tem apresentado avanços significativos, à medida que, a partir de 1988, passa a considerar criança e adolescente como sujeitos de direitos, prioridade absoluta e como pessoas em desenvolvimento. Dentro do novo contexto legal, chama o legislador os profissionais da saúde e da educação para contribuir na identificação dos casos de suspeita ou confirmação de maus-tratos contra a criança. Segundo o Estatuto da Criança e do Adolescente (arts. 13, 56 e 149), passa a ser obrigatória a notificação ao Conselho Tutelar pelos profissionais da saúde e da educação (arts. 13 e 
56 do ECA), sempre que verificarem uma suspeita ou confirmação de maus-tratos praticados contra seus pacientes ou alunos. A nova exigência legal tem contribuído enormemente para a identificação precoce de múltiplas formas de violência praticadas contra a criança e o adolescente, mas, de forma especial, aos de idade mais reduzida. Sabe-se, entretanto, que os dispositivos legais, por si só, não são capazes de reverter a dura realidade que nos cerca, caso não haja um efetivo envolvimento destas duas categorias profissionais com a prevenção, possibilitando não só conhecer os sintomas e os sinais indicativos de maus-tratos contra a criança, como também sentindo-se, cada vez mais, motivados a agir dentro dos novos parâmetros legais.

O novo, nesta virada de século, é a postura adotada pela legislação brasileira, que passa a lançar mão de vários dispositivos que se destinam a proteger a criança e o adolescente de inúmeras violências que historicamente o homem, em especial o adulto, praticava contra a criança, inclusive, com a conivência das regras legais que vigoravam em épocas passadas.

Há uma tendência mundial de onerar o agressor com sanções legais; mais de 50 países já tem legislação específica. Os índices americanos diminuíram depois da determinação de aumento de custos para os agressores. Há uma combinação de medidas de proteção e penalidades, como obrigatoriedade a sessões de aconselhamento ou tratamento para dependência química e/ou pagamento de sustento à família.

Para concluir, cabe-se ressaltar que o entusiasmo despertado no grupo pela rica convivência, funcionando como um espaço de diálogo e possibilitando novas e ricas reflexões apontam para as possíveis alternativas para lidar com o problema. A tolerância às diferenças, as trocas permitidas, respeitando os limites e os papéis de cada membro do grupo, representa o forte vínculo que torna a família o sustentáculo emocional do ser humano. Todas as iniciativas que permitam o reforço deste espaço de entendimento, utilizando, como diria Freud, as identificações e os fortes laços afetivos, permitem efetivas formas de lidar com conflitos em todos os níveis, especialmente os intrafamiliares.

\section{REFERÊNCIAS BIBLIOGRÁFICAS}

1. Alonso R. El psicoanalisis frente a la guerra. Buenos Aires (Argentina): Rodolfo Alonso, 1970.

2. Ministério da Saúde. Secretaria de Políticas de Saúde. Violência Intrafamiliar: Orientações para práticas em serviço. Brasília: MS; 2001

3. Oliveira MS, Flores RZ. Violência contra crianças e adolescentes na Grande Porto Alegre. In: Violência Doméstica. p. 71-86

4. Azambuja MRF. O caminho percorrido pela criança-vítima. In: Violência Doméstica. p.118-124.

5. Monteiro MC, Cabral MA, Morgado AF. Violências contra crianças e adolescentes: uma revisão bibliográfica. Arq Bras Pediat 1995; 2 (6): 153-156.

6. Lima,JB. As mais antigas Normas de Direito. 2 ed. Rio de Janeiro: Forense, 1983.

7. Gélis J. A individualização da criança. In: Ariès, P (org.). História da vida privada. Traduzido por Hildegard Feist. São Paulo: Companhia das Letras, 1991, v. 3.

8. Postman N. O desaparecimento da infância. Rio de Janeiro: Graphia, 1999.

9. Ariès $P$, Duby $G$. História da vida privada. Traduzido por Maria Lúcia Machado. São Paulo: Companhia das Letras, 1990, v. 2.

10. Perrot $\mathrm{M}$ (org.), Ariès $\mathrm{P}$, Duby G. História da vida privada. Traduzido por Denise Bottmann e Bernardo Joffily. São Paulo: Companhia das Letras, 1999, v. 4.

11. Ramos FP. A História trágico-marítima das crianças nas embarcações portuguesas do século XVI. In: Priore, MD (org.). História das Crianças no Brasil. São Paulo: Contexto, 1999.

12. <http://www5.who.int/violence injury prevention/ main.cfm?p=0000000682> Em: 14 outubro 2002.

13. Gonzáles RS. Saiba como dizer não à violência. Porto Alegre: [s.n.], 1995.

14. Azevedo MA, Guerra VNA. Infância e Violência Doméstica: fronteiras do conhecimento. 2. ed. São Paulo: Cortez, 1997.

15. Brum E. Apresentação. In: : Violência Doméstica. p.5-7.

16. Azevedo MA. (2001). Ponta do Iceberg. Disponível em <http:/www.usp.br/ip/laboratorios/lacri>. Acesso em 24 jul. 2002.

17. The Johns Hopkins Bloomberg School of Public Health. Population Reports: Como acabar com a violência contra as mulheres. In: Temas Mundiais de Saúde, 1999. Volume XXVII(4).

18. Organização Pan-americana da Saúde. Relatório sobre a saúde no mundo 2001: Saúde Mental: nova concepção, nova esperança. Brasil; 2001.

19. Marchiori H. Victimología: Homicidio en el grupo familiar. Revista Mexicana de prevención y readaptaçión social, 2000; 7: 49-68.

20. Alvarado-Zaldivar G, Moysén JS, Estrada-Martínez S, Terrones-González A. Prevalencia de violencia doméstica en la ciudad de Durango. Salud Publica de Mexico 2002.

21. Gianini R, Litvoc J, Neto JE. Agressão física e classe social. Rev Saúde Pública 1999; 33(2).

22. Cherpitel CJS, Rosovsky H. Alcohol consumption and casualities: a comparison of emergency room population in the United States and Mexico. J Stud Alcohol 1990; 51: 319-26.

23. Furniss T. O abuso sexual da criança. Tradução Mara Adriana Veríssimo Veronese. Porto Alegre: Artes Médicas, 1993 


\section{RESUMO}

Os recentes estudos sobre comportamento violento demonstram que uma grande e significativa gama de atos desta natureza ocorrem dentro do ambiente doméstico. A idéia do lar como local de proteção adquire uma perspectiva ameaçadora e sombria, propiciando e facilitando a ocorrência de condutas violentas. Sob tal perspectiva, o grupo propõe-se a discutir as diversas manifestações de violência doméstica e os diferentes determinantes envolvidos dentro de uma perspectiva multidisciplinar, procurando refletir sobre possíveis alternativas.

Descritores: Violência doméstica, violência intrafamiliar, doença mental.

\section{ABSTRACT}

Recent studies concerning violent behavior show that most of that violence takes place at home. Home, a place where a person seeks protection turns out to be a threatening and terrifying place due to violent behavior in the family. The authors discuss different manifestations of domestic violence and their determinants using a multidisciplinary perspective of the problem, and suggest possible alternatives.

Keywords: Domestic violence, intra familial violence, mental diseases.

Title: Domestic violence and its manifestations

Endereço para correspondência:

Vivian Peres Day

Av. Itaqui, 72/504

90460-140 - Porto Alegre - RS

E-mail: vivianday@uol.com.br

Copyright (c) Revista de Psiquiatria do Rio Grande do Sul - SPRS 